\title{
Winds of change in delivery of quality surgical care are not strong enough
}

T here is no question Canada and other large parts of the world have difficulty providing adequate care. Rural and not so rural communities are lacking total health care coverage. The continual downgrading of resources to care for all patients in Canada has resulted in a lack of critical care coverage zones, increasing wait times for even prioritized procedures and rapidly rising numbers of underemployed surgeons and other physicians. The last issue of $C F S$ included discussion of 2 options s $^{1,2}$ as well as a proposed plan $^{3}$ to solve some of the issues at hand.

I worry, however, about quality medical care. Quality of care monitoring has become a piecemeal affair with the use of patient databases and comparisons to other sector demographics. I think the measures proposed to help monitor how care is given are too little, too late. Certainly a family in northern Quebec, for example, will not have access to state-of-the-art neonatology services or even run-of-the-mill physiotherapy care. Delivery of these and other services by other practitioners educated through a Competency by Design (CBD) model - if it is ever revealed - may be part of the answer. Whether a family practitioner wants to spend a lot of time training for a rarely performed procedure has yet to be determined.

The enhanced surgical skill set necessary to be proficient seems daunting. And CBD testing with oral and written exams seems a little dated, especially for the physicians in rural settings. A combination of simulation training and telemedicine mentoring needs to mature to make this really possible. But in reality we almost have the tools to make this transition possible. Unfortunately, the health care system and the Canadian research institutes have been slow to respond. We need to treat rural medicine in more ways like delivery of care to a spacecraft.

Certainly large corporations like Google and Microsoft are now offering hardware that can be used to facilitate distance learning and delivery of health care. Although Google Glass was a consumer failure, the uptake by the medical community was much greater. The safe use of the glasses to oversee procedures being performed remotely by an expert is now well established. Microsoft launched a look-alike product aimed at making the wearer/treating surgeon able to see overlaid holograms, thereby allowing remote surgeons the possibility to map out 3-dimensional surgical plans on the patient in real time or to annotate the procedure as it happens. Remote sensing packages with cloud-driven oversight applications would make it simpler to keep healthy patients at home and recognize sick patients earlier in their disease states. Both would increase quality of care and decrease costs to the system.

Agreement among physicians on quality of care parameters is another important step we must take in order to make any health system change. I think that some of the debate about whether we can transfer high-level care to the rural setting would be clarified if we could just bring modern technology into the argument. Certainly, rural care cannot be as good or complete as urban care for major, uncommon diseases, but it could be a lot safer very quickly for the more common ailments.

\section{Edward J. Harvey, MD \\ Coeditor, Canadian fournal of Surgery}

Competing interests: E.J. Harvey is the Chief Medical Officer of Greybox Healthcare (Montreal) and Chairman of the Board of NXT-Sens Inc. (Montreal).

DOI: $10.1503 /$ cjs. 017615

\section{References}

1. Warnock G, Miles G. Why Canada needs networks to provide rural surgical care, including family doctors with essential surgical skills. Can F Surg 2015;58:367-8.

2. Vinden C, Ott MC. GPs with enhanced surgical skills: a questionable solution for remote surgical services. Can f Surg 2015;58:369-71.

3. Caron N, Iglesias S, Friesen R, et al. A proposal for the curriculum and evaluation for training rural family physicians in enhanced surgical skills. Can 7 Surg 2015;58:419-22. 